\title{
Reflexões sociolinguísticas sobre a libras (Língua Brasileira de Sinais)
}

\author{
Angelica Rodrigues \\ Universidade Estadual Paulista "Júlio de Mesquita Filho" (UNESP), \\ Araraquara, São Paulo, Brasil \\ angelica.rodrigues@fclar.unesp.br \\ Anderson Almeida da Silva \\ Universidade Federal do Piauí (UFPI) / Universidade Estadual de Campinas \\ (UNICAMP-PG), Parnaíba, Piauí, Brasil \\ andersonalmeida@ufpi.edu.br
}

DOI: http://dx.doi.org/10.21165/el.v46i2.1673

\begin{abstract}
Resumo
O objetivo, neste artigo, é discutir questões caras à Sociolinguística, como variação e mudança linguística, heterogeneidade e contato linguístico, tendo a libras (Língua Brasileira de Sinais) em perspectiva. Para isso, será necessário remeter a aspectos da gramática da libras, assim como da comunidade de falantes, isto é, sua sócio-história. Partimos dos pressupostos teóricos desenvolvidos pela Sociolinguística que, embora sejam mais explorados tendo em vista as línguas faladas, devem ser considerados em discussões cujo objetivo seja desconstruir paradigmas a respeito das concepções de língua, de contato linguístico e de variação e mudança linguística nas línguas sinalizadas.
\end{abstract}

Palavras-chave: sociolinguística; libras; contato linguístico; variação e mudança linguística.

\section{Sociolinguistics reflections on Libras - Brazilian Sign Language}

\begin{abstract}
This paper aims to discuss the main issues in Sociolinguistics, such as variation and linguistic change, heterogeneity and linguistic contact, concerning to the Libras (Brazilian Sign Language). Primarily, we bring into discussion the grammatical aspects of Libras, as well as the aspect of its speech community, that is, its social-historical contextualization. The theoretical assumptions of Sociolinguistics are vastly explored among the spoken languages worldwide. However, there are few initiatives of exploring the sociolinguistics' concepts of language, linguistic contact, variation and linguistic change towards a revision of the main misleading concepts applied to sign languages.
\end{abstract}

Keywords: sociolinguistic; Libras; linguistic contact; variation and linguistic change.

\section{Introdução}

Se a linguística pode ser considerada uma ciência nova, a linguística das línguas de sinais é ainda mais recente e pouco conhecida até mesmo entre os linguistas que historicamente têm se voltado mais fortemente para a análise de línguas faladas. No Brasil, os estudos linguísticos de línguas sinalizadas ganharam força nos anos 1990, depois dos trabalhos pioneiros de Ferreira-Brito (1984, 1995), Felipe (1989) e mais 
recentemente Quadros (2003) e Quadros e Karnopp (2004), que publicaram, dentre outros, dissertações, teses e livros sobre a língua dos surdos brasileiros.

Nesse contexto, a libras tem ganhado, a partir da última década, principalmente, destaque nos debates voltados para questões tanto pedagógicas quanto linguísticas relativas à educação de surdos. No entanto, no que diz respeito ao ensino e à aprendizagem de libras por surdos e ouvintes, é possível encontrar referências às noções de "erro" e aos conceitos de "certo" e "errado" como um reflexo tanto do sentimento dos próprios falantes em relação a sua própria língua quanto de práticas pedagógicas tradicionais que elegem um padrão de língua a ser seguido por todos os membros da comunidade de fala. Esse "sentimento" e esse debate não divergem do observado em contextos de ensino e aprendizagem da língua oral, todavia, para o português, esses "préconceitos" são amplamente discutidos na literatura, inclusive nos PCNs, há mais de três décadas. Por ser uma língua silente, não sonora, muitos acreditam que as línguas de sinais estariam de certa forma "imunes" aos efeitos da estigmatização de formas linguísticas largamente estudados nas línguas orais, principalmente a partir de Labov (2008).

Portanto, neste artigo, que é um resumo das ideias apresentadas no minicurso Reflexões sociolinguísticas sobre a libras (Lingua Brasileira de Sinais) durante o $64^{\circ}$. Seminário do GEL, nossa intenção é destacar, a partir da revisão dos pressupostos clássicos da Sociolinguística, os processos relacionados à variação e mudança presentes nas línguas de sinais, visando, sobretudo, apontamentos que possam fomentar trabalhos futuros nesse campo.

O artigo está organizado do seguinte modo: inicialmente defenderemos a legitimidade da libras como língua natural a partir de pressupostos sociolinguísticos, buscando destacar sua natureza heterogênea. Num segundo momento, discutiremos a realidade sociolinguística da libras num contexto de bilinguismo português e libras. Finalmente, abordaremos a temática da variação e da mudança linguística aludindo, principalmente, a questões de ensino e aprendizagem da libras por surdos e ouvintes. As conclusões e as referências bibliográficas serão apresentadas no final do artigo.

\section{O que é língua?}

Uma das principais demandas das comunidades surdas é o reconhecimento das línguas de sinais como línguas naturais, assim como as línguas orais. Esse reconhecimento é fundamental porque apenas com a legitimação de sua língua e, consequentemente, de sua cultura, os surdos podem ter garantidos seus direitos relacionados à sua identidade linguística.

A história dos surdos é marcada por períodos de avanço no reconhecimento de seus direitos e capacidades, mas também por períodos de total desrespeito, o que determinou, inclusive, a proibição das línguas de sinais por aproximadamente um século, desde o congresso de Milão em 1880 até meados de 1980. Em nome da brevidade, não exploraremos esse aspecto da história dos surdos e nos concentraremos mais especificamente na história da Linguística das Línguas de Sinais, buscando enfatizar as contribuições da linguística para a legitimação das línguas de sinais (daqui em diante, LS) como línguas naturais. Nesse sentido, destacamos as pesquisas de W. Stokoe (1960) que foram extremamente importantes para a legitimação das línguas sinalizadas. Ao propor 
inicialmente três parâmetros para descrever a estrutura sublexical da Língua de Sinais americana $^{1}$, o autor consegue mostrar que, assim como as línguas orais, as línguas sinalizadas possuem estrutura gramatical que pode ser analisada segundo diferentes níveis, como fonologia, morfologia e sintaxe. Por essa razão, o trabalho pioneiro de Stokoe (1960) é recorrentemente usado para legitimar as línguas de sinais que são julgadas, muitas vezes, como mímicas ou pantomimas.

Considerados um marco no desenvolvimento da linguística das LS, os estudos de Stokoe (1960) se desenvolveram dentro do paradigma estruturalista, que partia de uma concepção de língua marcada pelo pensamento saussuriano de que língua é um sistema (langue) que se opõe à fala (parole). Uma vez que é a partir de Saussure (2002) que, ao discutir, pela primeira vez, o objeto de estudo da linguística, a língua, temos a proposição da linguística como ciência, os estudos estruturalistas sobre as LS concentraram-se na descrição das línguas sinalizadas como um sistema estruturado, tal como proposto pelo linguista genebrino.

Embora a língua seja descrita como um fato social no Curso de Linguística Geral (SAUSSURE, 2002), a metodologia da pesquisa estruturalista retira da língua tudo o que é social, concentrando as análises nos fatos de língua que podem ser usados para demonstrar a sistematicidade da língua, como o sistema de oposições fonológicas, por exemplo.

É fato pacífico que não há língua sem gramática, isto é, não há língua em que não se possam depreender aspectos fonológicos, morfológicos e sintáticos. Todavia, é preciso refletir sobre uma questão fundamental: nosso entendimento daquilo que seria uma língua está restrito à descrição de sua estrutura gramatical? O que é, afinal, a língua?

Saussure, ao formular os pressupostos daquilo que passaria a ser reconhecido como a ciência da linguagem, afirma que, na linguística, diferente de outras ciências, é a visão do pesquisador que define o objeto de estudo. Desse modo, o objeto de estudo da linguística, isto é, a língua, será definido de diferentes maneiras a partir da perspectiva do analista.

Os pressupostos estruturalistas são repensados a partir do desenvolvimento de outras duas correntes de pensamento, a saber, gerativismo e funcionalismo. Embora a concepção de língua no modelo gerativista não se afaste consideravelmente daquela proposto em Saussure, é no desenvolvimento do funcionalismo que encontramos uma nova concepção de língua e, consequentemente, uma nova linguística, em que não se discute oposições entre langue e parole (SAUSSURE, 2002) nem entre competência e desempenho (CHOMSKY, 1965).

O modelo funcionalista, ao definir a língua como um produto de interação, afastase da ideia de uma gramática pré-concebida e propõe a existência de uma gramática emergente (HOPPER, 1987), que resulta de pressões de uso ligadas às necessidades comunicativas e expressivas dos falantes.

\footnotetext{
${ }^{1}$ São eles: configuração de mãos, localização no espaço e movimento. Mais tarde, dois novos parâmetros são propostos, a saber, a orientação da mão (BATTISON, 1978) e os elementos não-manuais (LIDDELL, 1991).
} 
Todavia, é basicamente a partir de Weinreich, Labov e Herzog (2006) (WLH daqui em diante) e das primeiras pesquisas sociolinguísticas empreendidas principalmente por William Labov na década de 1960, que é proposto o desenvolvimento de uma perspectiva efetivamente social para a linguística, em que a língua é entendida como um sistema heterogêneo em uso numa comunidade de fala e sujeita a pressões linguísticas e extralinguísticas (sociais). A fim de enfrentar os problemas descritivos descartados na abordagem estruturalista, a sociolinguística se consolida a partir da eleição do estudo da variação e da mudança linguística, atributos vinculados grosso modo às noções de langue e desempenho. WLH defendem que qualquer análise linguística precisa dar conta daquilo que é parte constitutiva e fundamental de toda língua, a saber, a mudança linguística, e que fora, de certo modo, deixado de lado pelos estruturalistas, ocupados principalmente com a descrição sincrônica. A problematização do pensamento saussuriano é construída por WLH a partir da própria definição estruturalista de sistema: "se uma língua tem de ser estruturada, a fim de funcionar eficientemente, como é que as pessoas continuam a falar enquanto a língua muda, isto é, enquanto passa por periodos de menos sistematicidade?" (WEINREICH; LABOV; HERZOG, 2006, p. 87). A solução para o dilema seria o rompimento da identificação entre estruturalidade e homogeneidade. Os autores propõem, portanto, um modelo de análise linguística que seja capaz de descrever a heterogeneidade ordenada, ou seja, a variação, considerando que nem toda variação leva à mudança, mas toda mudança pressupõe um período anterior de variação (WEINREICH; LABOV; HERZOG, 2006, p. 126).

Essa correlação entre variação e mudança linguística instaura um modelo de análise linguística que assume a língua como um processo dinâmico, em que não é possível a separação de fenômenos diacrônicos e sincrônicos. O estado sincrônico de qualquer língua é resultado dos processos diacrônicos que se sucederam ao longo do tempo. Sendo assim, uma análise estritamente sincrônica é uma análise sociolinguisticamente agnóstica.

Desse modo, para a sociolinguística, não existe língua fora do contexto social e toda língua é um conjunto de variedades; língua é um sistema constituído de heterogeneidade ordenada em que fatores linguísticos e extralinguísticos funcionam como condicionadores da variação e da mudança. A língua, nessa perspectiva, portanto, não pode ser analisada separada dos seus contextos de usos e, consequentemente, de seus falantes. Considerando que não há língua com apenas um falante, as línguas devem ser analisadas no contexto social em que falantes de diferentes idades, origem social, etnia, graus de escolaridade, sexo e gênero interagem. A gramática não é produto acabado e fechado que esses falantes devem aprender. A gramática é construída justamente por esses falantes em situações de interação em que sentidos são negociados. Desse modo, a história interna de uma língua não se desvincula da sua história externa, ou seja, da história de seus falantes.

Nesse sentido, cabe remeter às definições de usuário/falante apresentadas em Neves (2002):

$\checkmark$ No ser que fala, no que chamamos de usuário da língua, está, então, a gramática.

$\checkmark$ A imagem do usuário - que é o homem que fala - precedeu a da gramática.

$\checkmark$ Ela está nele: na sua fala há uma gramática, que ele possui. 
Se a gramática está no usuário, ele não é um aprendiz, pois não é possível aprender o que já se sabe. Não existe gramática como produto acabado que se configurou num determinado tempo e espaço e assim permanecerá a despeito de reconfigurações sociais a que seus falantes sejam submetidos. A gramática está num movimento contínuo de estruturação e reestruturação motivado pelas necessidades comunicativas de seus usuários. E sendo as necessidades comunicativas e a identidade dos falantes diferentes, não podemos esperar que a língua seja a mesma para todos os falantes em todas as situações de comunicação. Por isso, não podemos dizer, por exemplo, que a Língua Portuguesa ou Inglesa ou a libras sejam únicas e homogêneas. Elas são todas, na verdade, um conjunto de variedades a que se atribui um rótulo. Se pensarmos, por exemplo, nas variedades brasileiras do português, não é possível dizer onde começa e onde termina a variedade mineira ou paulista (caipira). Aquilo que chamamos de português constitui-se como um conjunto de regras mais ou menos regulares que são compartilhadas por falantes. O que garante a unidade dessa língua, a despeito da intensa variação dialetal, é a normatização. A norma, difundida na escola através do material didático, na imprensa e nos documentos oficiais, garante um certo nível de unidade, que é mais perceptível na escrita formal. O que deve ser destacado, no entanto, é que, apesar da diversidade linguística, todos os falantes de português são capazes de se entender mutuamente. Como afirmam WLH, a variação dialetal faz parte da competência monolíngue do falante.

No que diz respeito à libras, pesquisas como a de Xavier e Barbosa (2014) e Andrade (2013) mostram que há variação no nível fonológico da sinalização dos surdos de diferentes dialetos, e considerando diferentes variáveis.

Todavia, apesar dos avanços das pesquisas sociolinguísticas, é comum ouvirmos na comunidade surda sinalizadores se referirem negativamente a outros sinalizadores que usam uma espécie de libras misturada com o Português, comumente denominada de Português sinalizado ${ }^{2}$. Há também casos em que sinalizadores realizam, com uma mão só, sinais feitos, a priori, com duas mãos - o que pode soar como um deslize fonológico, a exemplo de expressões como "os menino", "praca", "bicicreta", "nóis vai" tão repreendidas pelos falantes de Português, e que acabam sendo objeto de preconceito linguístico. Utilizando-se do mesmo "argumento" de que "isso não é Português", muitos sinalizadores dizem "isso não é libras" ao se depararem com efeitos dialetais. Esse preconceito usa a variedade padrão ${ }^{3}$ como referência única de língua e atribui aos falantes das variedades não-padrão o estigma do "analfabeto" ou o dos "sem gramática".

Se toda língua se constitui a partir de uma gramática, não é possível que qualquer produção linguística inteligível seja produzida fora de uma gramática. Todavia, se toda

\footnotetext{
${ }^{2}$ Mais comum entre os surdos mais escolarizados pelo fato de estarem em contato com textos em língua portuguesa. A comunidade surda, no geral, não possui níveis altos de escolarização, e daí decorre o estranhamento com as possíveis variações encontradas na língua pela situação de contato. O Português sinalizado seria uma situação em que um falante da libras ao invés de utilizar a gramática mais estável da libras, se utilizaria de: i. expressões idiomáticas do Português que são traduzidas literalmente para a libras; ii. da ordem sintática mais conveniente ao Português (linear) em um determinado contexto de fala, ao invés de uma ordem que soaria mais claro na língua sinalizada (construções em simultaneidade). Estamos cientes da diferença entre construções agramaticais na língua de sinais, que são ininteligíveis, de outras que são menos aceitas. O que se percebe é uma certa intolerância com os sinalizadores que apresentam um maior contato com o português.

${ }^{3}$ No caso das línguas de sinais, nem sempre a variedade padrão é a de mais prestígio social; pode ser, literalmente, a mais difundida.
} 
língua é constituída de variedades, então entre seus falantes circulam várias gramáticas sendo todas elas igualmente complexas e completas.

A sociolinguística, nesse sentido, pode ser usada para desconstruir esses préconceitos que sustentam as orientações pedagógicas e o senso comum no que diz respeito à língua. Nesse sentido, discutiremos nas próximas seções deste artigo dois conceitos importantes para a sociolinguística, a saber, contato linguístico e variação e mudança linguística, buscando correlacioná-los à realidade sociolinguística da libras no Brasil.

\section{Contato linguístico}

A libras existe no Brasil há pelo menos 159 anos, pois no ano de 1857 foi fundado no Rio de Janeiro o primeiro Instituto Nacional para Educação de pessoas Surdas, o INES. Anteriormente à criação do instituto, a língua já existia nas ruas, nas casas, com menor difusão e estabilidade, no seio das comunidades surdas. Somente a partir da institucionalização da educação de surdos, surgiram os primeiros registros lexicográficos da língua e o interesse de profissionais em garantir a sua sobrevivência e difusão. Atualmente, a libras não é um idioma oficial da nação brasileira, mas é reconhecida oficialmente pela lei 10.436/2002 e pelo decreto 5.626/2005. Ela existe e pode ser utilizada ampla e indistintamente pelos surdos brasileiros, que tiveram, com a aprovação dessas leis, suas especificidades linguísticas reconhecidas.

A ideia equivocada de que o Brasil é um país monolíngue já foi rebatida em inúmeros trabalhos (LEITE; CALLOU, 2002) em que se discutem a realidade multilíngue e multidialetal do país, onde convivem, ao lado das variedades do português, as línguas nativas brasileiras, as línguas de imigrantes e as línguas de sinais ${ }^{4}$. Uma vez que a língua oficial do país é o português, toda instrução formal é dada nessa língua, o que tem desdobramentos na realidade linguística dos falantes não-nativos do português ou bilíngues. Grande parte da população não falante de português acaba inevitavelmente tendo o português como língua de instrução unicamente, salvo raras exceções de escolas bilíngues. No que diz respeito à comunidade surda, o contato com o português pode se efetivar de duas maneiras. Os surdos oralizados aprendem apenas o português ou são bilíngues. Os surdos não oralizados usam o português somente na modalidade escrita, sendo a libras considerada sua única língua materna.

Seja como for, o fato de os surdos estarem inseridos num contexto em que o português figura como língua majoritária faz com que a libras, assim como outras línguas minorizadas, se constituam como uma ilha linguística num mar de português. Desse modo, o contato com o português é inevitável.

Segundo Thomason e Kaufman (1988), há duas pré-condições para que haja empréstimos entre línguas, quais sejam, contato social intenso e falantes bilíngues. Considerando que, além dos surdos, há também ouvintes usuários de libras, podemos concluir que a situação sociolinguística da comunidade surda no Brasil é de bilinguismo, em maior ou menor grau. Como afirma Adam (2012, p. 844), há consenso atualmente de

\footnotetext{
${ }^{4}$ Além da libras, que é a língua de sinais majoritariamente falada pelos surdos brasileiros, alguns trabalhos remetem à existência de línguas de sinais nativas, como a ka'apor (FERREIRA-BRITO, 1984), terena (SUMAIO, 2014) e a língua de sinais emergente Cena (PEREIRA, 2013).
} 
que a comunidade surda é uma comunidade bilíngue com indivíduos surdos com vários graus de fluência na língua oral e de sinais da comunidade. Ainda segundo esse autor, em contextos sociolinguísticos similares, o efeito do contato entre línguas orais e sinalizadas é igual ao do contato entre línguas orais (ADAM, 2012).

O efeito principal do contato linguístico é o empréstimo (borrowing), que pode ter desdobramentos distintos em cada situação. Pensando especificamente no caso da libras, podemos dizer que esses empréstimos se dão no nível lexical através, por exemplo, do uso de sinais soletrados ${ }^{5}$ e também no nível morfossintático com o empréstimo de preposições (para e em) e conjunções (se, mas e $e^{6}$ ).

Uma análise do resultado desses empréstimos para a gramática da libras ainda está por ser feita, mas é muito comum ouvir membros da comunidade se posicionando contrariamente a esses empréstimos. O argumento principal seria o de que esses empréstimos são português, não libras. Tendo em vista que não é possível explorar mais profundamente a questão do empréstimo linguístico, restringiremos nossa reflexão aqui apenas aos casos envolvendo datilologia.

Em relação ao uso da datilologia na Língua Americana de Sinais (daqui em diante, ASL) alguns trabalhos apresentam perspectivas diversas. Battison (1978), por exemplo, baseou-se no fato de que datilologia era inglês, não ASL. Outros pesquisadores, porém, como Davis (1989), argumentam que datilologia não é inglês. Davis sustenta que datilologia é ASL porque os morfemas em ASL nunca são emprestados de um contexto ortográfico do inglês, eles são usados para representar um contexto ortográfico. Valli e Lucas (1992, p. 41) enfatizam que empréstimos de datilologia são reestruturados para se adequar à fonologia da língua de sinais.

Evidências psicolinguísticas acerca desse fenômeno são oferecidas por Waters et al. (2007, p. 1287) que investigaram a ativação de zonas cerebrais (lateralidade) de palavras escritas, imagens, sinais e datilologia, buscando verificar se a datilologia era processada como escrita ou sinalização. Os autores observaram que a datilologia era processada em áreas do cérebro similares às usadas para os sinais da LS e distintas das envolvidas em escrita.

No que diz respeito à aquisição, Padden e LeMaster (1985), Akamatsu (1985) e Blumenthal-Kelly (1995) apontam que crianças reconhecem palavras soletradas manualmente muito antes de aprenderem a "soletrar", o que pode evidenciar que essas palavras soletradas são consideradas sinais e não palavras emprestadas da língua oral.

Ademais, itens lexicais podem ser criados, segundo Brentari e Padden (2001) e Sutton-Spence (1994), através da composição de datilologia e sinais, como, por exemplo,

\footnotetext{
${ }^{5}$ Sinais soletrados são assim denominados os sinais que são compostos basicamente por letras do alfabeto. Entretanto, a diferença entre a soletração de um nome próprio como A-N-A e de um sinal soletrado como D-V-D, é que no primeiro caso não há nenhuma alteração na prosódia da soletração, já nestes últimos observa-se que a soletração é mais rápida, pode haver inclusive a lenição fonológica de parte das letras soletradas, garantindo mais agilidade e rapidez para a prosódia do sinal. Por isso, nomes que são constantemente soletrados tendem a ser incorporados no léxico das línguas de sinais, depois de sofridos os devidos ajustes. Isso não é estranho se pensarmos no empréstimo de palavras de origem inglesas e francesas para o português brasileiro, por exemplo.

${ }^{6}$ Rodrigues (2015) chama atenção para casos em que a letra 'E' aparece como uma conjunção coordenada aditiva, o que não invalida a análise da influência pelo contato.
} 
soletrado manualmente como $-P$ - C e o sinal de mouth (boca) para Portsmouth (nome de uma cidade).

Há também o que é chamado de processo de nacionalização da datilologia (KYLE; WOLL, 1985; SUTTON-SPENCE, 1994; CORMIER; TYRONE; SCHEMBRI, 2008), através do qual um sinal com soletração manual se torna um sinal. Isso ocorre quando: (a) as formas se adéquam aos contornos fonológicos do léxico nativo; (b) parâmetros da forma ocorrem no léxico dos nativos; (c) elementos nativos são adicionados; (d) elementos não nativos são reduzidos (perda de letras); e (e) elementos nativos são integrados com elementos não nativos (CORMIER; TYRONE; SCHEMBRI, 2008 apud ADAM, 2012). Temos dois grupos de sinais soletrados em libras, observando o comportamento descrito acima: sinais que continuam sendo soletrados ipsis literis a sua grafia na língua oral (por exemplo: $C-D, L-I-X-O, O-U$ etc.) e sinais que sofreram algum tipo de redução fonológica ou alteração prosódica (por exemplo: $N-U-N$ para "nunca", $V-I$ para "vai" e $L-I-N-D-O$ que é soletrado com alterações prosódicas específicas). Essas mudanças não são previsíveis pela teoria para nenhum grupo de palavras e somente são implementadas pela aceitação da comunidade de fala da libras.

\section{Variação e mudança linguística}

Um dos principais valores associados à língua está presente fortemente na escola e, por conta disso, é assumido pela grande maioria dos falantes como sendo verdadeiro. Esse pré-conceito prevê que a língua é uma entidade homogênea e pura e está representada completamente nas gramáticas tradicionais e na obra dos escritores clássicos da nossa literatura. Expressões e palavras que estejam em desacordo com a norma prevista nessas obras consistiriam em uma ameaça à pureza da língua. Essa ameaça pode se configurar tanto em estruturas observáveis na fala e na escrita de brasileiros e identificada como um erro ou desvio em relação àquilo que é convencionalmente chamado de norma culta, quanto em palavras e expressões estrangeiras. Nos dois casos, esses usos são condenados por gramáticos tradicionais, cabendo à escola a sua "correção".

Há uma associação forte entre língua e homogeneidade e pureza (língua pura), estando a língua sujeita a ameaças externas (estrangeirismos, empréstimos) e internas (variedades populares).

Por que dizemos que essa ideia é equivocada? O português é uma língua românica, descendendo, portanto, do latim. Embora muitas palavras da nossa língua tenham origem latina e grega, num exercício rápido de consulta aos dicionários de português, encontramos inúmeras palavras estrangeiras, cuja origem é ignorada pela maioria dos brasileiros. As palavras almofada, almoxarifado, alfaiate, por exemplo, são de origem árabe e representam o registro linguístico do período que os árabes dominaram a Península Ibérica entre os séculos VIII e XV d.C. As palavras cavalo, gato, cabana e cerveja são de origem celta. Já as palavras guerra, albergue, fralda e branco são de origem germânica. Apesar disso, nós como falantes não analisamos estes fatos no momento de fala, e eles somente interessam a uma pesquisa histórica da língua. Percebese, então, que os empréstimos linguísticos não ameaçam a existência de nenhuma língua no mundo, do contrário, dão sinais de sua vitalidade e constituem registros linguísticos da história externa de uma língua. 


\section{Existe língua pura?}

Um dos grandes mistérios da humanidade é o surgimento da primeira língua. Perguntas acerca da existência de uma língua original única e talvez divina permanecem incentivando respostas especulativas. As pesquisas em Linguística Histórica, através dos métodos comparativos e de reconstrução interna, possibilitaram a elaboração de árvores genealógicas de famílias linguísticas. Olhando para esses dados, parece impossível que sejamos capazes de encontrar uma origem comum entre as diversas línguas vivas ou mortas faladas no mundo. O que sabemos, no entanto, é que a capacidade da linguagem colocou o homem à frente na escala evolutiva e que a fala representa um marco na evolução da nossa espécie. Nesse processo de evolução, os gestos têm papel fundamental e alguns trabalhos discutem sua importância no desenvolvimento da comunicação humana (STOKOE, 1960).

Se, por um lado, não podemos encontrar evidências sobre a primeira ou primeiras línguas, por outro, temos descrições sobre o surgimento de novas línguas e a partir disso somos capazes de entender melhor como nasce uma língua.

Aquilo que identificamos como português, por exemplo, nasce no século XI, sendo sua história interna reflexo de sua história externa. A partir da instauração do Reino de Portugal por D. Afonso Henriques, a Língua Portuguesa começa a se configurar de modo, inclusive, a se distinguir da Língua Castelhana. A passagem do latim para o português não é, entretanto, abrupta. Até que o português fosse normatizado, no século XVI, com a publicação das primeiras gramáticas portuguesas, podemos entender que inúmeras variedades eram faladas na região de Portugal. Dessas variedades restaram algumas evidências, como as poesias trovadorescas, que apontam fortemente para um contato linguístico. Considerando os séculos iniciais da emergência do português, podemos concluir, desse modo, que essa língua nasce da mistura de diferentes línguas e variedades e que sua configuração lexical e morfossintática emerge num contexto sociocultural marcado pela diversidade linguística. Portanto, o português não tem uma origem "pura" como muitos defendem.

A história da emergência do português não é distinta da história de outras línguas. Para nos atermos ao contexto dessa língua, podemos citar o surgimento dos crioulos de base portuguesa, como o crioulo cabo-verdiano ou kauberdianu, por exemplo. Ao contrário do senso comum, não existe língua pura, pois toda língua surge do contato. Esse pressuposto vale tanto para as línguas orais quanto para as línguas sinalizadas. Souza e Segala (2009) fazem um histórico do surgimento de várias línguas de sinais, inclusive a libras. O que todas essas línguas têm em comum considerando sua origem é o contexto multilingual e multidialetal que precederam sua emergência.

Suppalla (2008, p. 22) aponta que os estudos sobre a emergência e desenvolvimento (mudança) nas LS estiveram por muito tempo fora do escopo das pesquisas em linguística das LS em razão da percepção equivocada de que processos históricos "naturais", como empréstimos, por exemplo, serviram para assinalar uma perspectiva de que as LS são "impuras".

O contato linguístico, ou seja, o bilinguismo prolongado resulta em mudança linguística. $\mathrm{O}$ fato evidente é que todas as línguas, orais e sinalizadas, são constituídas de heterogeneidade, sendo a variação e a mudança propriedades inerentes em todos os casos. Portanto, se, por um lado, a origem da libras remete à Língua de Sinais Francesa (LSF), 
a convivência permeada pelo bilinguismo em relação ao português aponta inevitavelmente para a configuração de uma língua heterogênea, como qualquer outra língua natural.

Ainda que se acredite que empréstimos, inovações (mudanças) linguísticas e contato linguístico constituam uma ameaça a determinada língua, nenhuma dessas situações põe em risco qualquer língua. Uma língua só morre quando morrem seus falantes ou se por algum fator sócio-histórico esses sejam impedidos ou deixem, com o tempo, de usar sua língua nativa. São situações extremas que levam à morte de uma língua, como guerras, processos de colonização e aculturação.

\section{Considerações finais}

A diversidade linguística tem diminuído no mundo e línguas minorizadas perdem espaço para as línguas de prestígio, de estado. Todavia, não é combatendo a diversidade que garantiremos a valorização de línguas minorizadas.

A partir desta exposição, pode-se afirmar que a fixação de quaisquer mudanças que tenham se iniciado por questões de contato entre línguas diferentes é de responsabilidade total da sua comunidade de fala.

Essa discussão é oportuna também para esclarecer aos profissionais da área de línguas de sinais sobre a intolerância que, muitas vezes, se fomenta sobre os diversos 'falares' da libras no Brasil. Muitos sinalizadores, pautados na ideia de que a sua forma de falar é a correta, estimulam a intolerância às questões da variação, e acabam por impor um julgamento daquilo que seriam para eles sinais "certos", "errados", "melhores" e "piores". Esse processo é idêntico ao que vivenciamos nas línguas orais, identificado como preconceito linguístico.

Uma particularidade das questões sociolinguísticas envolvendo a libras é que, geralmente, há uma resistência dos surdos aos sinais que são literalmente inventados (criados) em contextos educacionais, como termos específicos de área e, ainda, a variação apresentada por falantes mais escolarizados, a quem se atribui, por exemplo, uma versão da libras mais parecida como uma tradução literal do português. Percebe-se, então, que o preconceito não se dá somente em relação aos grupos de menor prestígio social, mas também com os que muito ascendem e terminam por distanciarem-se do vernáculo urbano da libras. A prova é que muitos surdos não escolarizados dizem não compreender os surdos mais escolarizados, e estes, a despeito da resistência dos demais, são tidos como os que mais sabem a língua. Esta é uma reflexão que pretendemos desenvolver futuramente em outro artigo.

Concluímos que reconhecer a realidade sociolinguística da libras, atestando o que há de consenso e dissenso entre seus falantes, também é uma forma de legitimar a língua da comunidade surda brasileira como uma língua natural, sujeita, portanto, à variação e à mudança linguística. 


\section{REFERÊNCIAS}

ADAM, R. Language contact and borrowing. In: PFAU, R., STEINBACH, M.; WOLL, B. (Ed.). Sign language: an international handbook. Berlin: De Gruyter Mouton, 2012. p. 841-861.

ANDRADE, W. T. L. de. Variação fonológica da LIBRAS: um estudo sociolinguístico de comunidades surdas da Paraíba. 2013. 142 f. Tese (Doutorado em Linguística) Programa de Pós-graduação em Linguística, Universidade Federal da Paraíba, João Pessoa, 2013.

AKAMATSU, C. T. Fingerspelling Formulae: A Word is More or Less than the Sum of Its Letters. In: STOKOE, W.; VOLTERRA, V. (Ed.). Sign Language Research '83. Silver Spring, MD: Linstok Press, 1985. p. 126-132.

BATTISON, R. Lexical Borrowing in American Sign Language. Silver Spring, MD: Linstok Press, 1978.

BLUMENTHAL-KELLY, A. Fingerspelling Interaction: A Set of Deaf Parents and Their Deaf Daughter. In: LUCAS, C. (Ed.). Sociolinguistics in Deaf Communities. Washington, DC: Gallaudet University Press, 1995.

BRENTARI, D.; PADDEN, C. Native and Foreign Vocabulary in American Sign Language: A Lexicon with Multiple Origins. In: BRENTARI, D. (Ed.). Foreign Vocabulary in Sign Languages: A Cross-Linguistic Investigation of Word Formation. Mahwah, NJ: Lawrence Erlbaum, 2001. p. 87-119.

CHOMSKY, N. Aspects of the Theory of Syntax. Cambridge, Mass.: MIT Press, 1965.

CORMIER, K.; TYRONE, M.; SCHEMBRI, A. One Hand or Two? Nativisation of Fingerspelling in ASL and BANZSL. In: QUER, J.; PFAU, R. (Ed.). Sign Language and Linguistics 11, 2008. p. 3-44.

DAVIS, J. Distinguishing Language Contact Phenomena in ASL Interpretation. In: LUCAS, C. (Ed.). The Sociolinguistics of the Deaf Community. San Diego, CA: Academic Press, 1989. p. 85-102.

FELIPE, T. A estrutura frasal na LSCB. In: Anais do IV Encontro Nacional da ANPOLL. Recife, 1989. p. 663-672.

FERREIRA-BRITO, L. 1984. Similarities and differences in two Brazilian Sign Languages. Sign Language Studies, Spring, v. 42, p. 45-56, 1984. 1995. . Por uma gramática das línguas de sinais. Rio de Janeiro: Tempo Brasileiro,

HOPPER, P. J. "Emergent Grammar". In: Proceedings of the Thirteenth Annual Meeting of the Berkeley Linguistics Society, 1987. p. 139-157.

KYLE, J.; WOLL, B. Sign Language: the Study of Deaf People and their Language. Cambridge: Cambridge University Press, 1985.

LABOV, W. Sociolinguistic Patterns. Philadelphia: University of Pennsylvania Press, 1972. [Padrões Sociolinguísticos. Tradução de Marcos Bagno, Marta Scherre e Caroline Cardoso]. São Paulo: Parábola, 2008. 
LEITE, Y.; CALLOU, D. Como falam os brasileiros. Rio de Janeiro: Jorge Zahar Editor, Série Descobrindo o Brasil, 2002.

LIDDELL, S. K. Structures for representing handshape and local movement at the phonemic level. In: FISCHER, S. D.; SIPLE, P. Theoretical Issues in Sign Language Research. v. 1. Chicago: University Chicago Press, 1991. p. 37-65.

NEVES, M. H. de M. A gramática: história, teoria e análise, ensino. São Paulo: Editora UNESP, 2002.

PADDEN, C.; LEMASTER, B. An Alphabet on Hand: The Acquisition of Fingerspelling in Deaf Children. Sign Language Studies, 47, p. 161-172, 1985.

PEREIRA, É. L. “Fazendo cena na cidade dos mudos”: surdez, práticas sociais e uso da língua em uma localidade no sertão do Piauí. 2013. 380 f. Tese (Doutorado em Antropologia Social) - Programa de Pós-Graduação em Antropologia, Universidade Federal de Santa Catarina, Florianópolis, 2013.

QUADROS, R. M. de. Phrase Structure of Brazilian Sign Language. In: Crosslinguistic perspectives in sign language research. Selected papers from TISLR 2000. Signum Press: Hamburg, 2003. p. 141-162.

QUADROS, R. M.; KARNOPP, L. B. Lingua de Sinais Brasileira. Porto Alegre: Artmed, 2004.

RODRIGUES, A. Conjunções em sentenças complexas em libras. Trabalho apresentado. Jornadas de Linguística Descritiva. UFSCar, 2015.

SAUSSURE, F. de. Curso de lingüistica geral. Organização de Charles Bally e Albert Sechehaye com a colaboração de Albert Riedlinger. Tradução de Antônio Chelini, José Paulo Paes e Izidoro Blikstein. 24. ed. São Paulo: Pensamento-Cultrix, 2002.

SOUZA, R. B.; SEGALA, R. R. A perspectiva social na emergência das línguas de Sinais: a noção de comunidade de fala e idioleto segundo o modelo teórico laboviano. In: QUADROS, R. M.; STUMPF, M. R. (Org.). Estudos surdos IV. Petrópolis: Arara Azul, 2009. p. 21-48. Disponível em: $<$ http://portal.sme.prefeitura.sp.gov.br/Portals/1/Files/19190.pdf $>$. Acesso em: 02 jul. 2016.

STOKOE, W. C. Sign language structure. An outline of the visual communication system of the American deaf. Studies in Linguistics Occasional Papers 8. Buffalo: University of Buffalo Press, 1960. [Re-issued 2005, Journal of Deaf Studies and Deaf Education, 10, p. 3-37].

SUMAIO, P. A. Sinalizando com os terena: um estudo do uso da LIBRAS e de sinais nativos por indígenas surdos. 2014. 124 f. Dissertação (Mestrado em Linguística e Língua Portuguesa) - Faculdade de Ciências e Letras, Universidade Estadual Paulista, Araraquara, 2014.

SUPALLA, T. Sign Language Archeology: Integrating Historical Linguistics with Fieldwork on Young Sign Languages. In: QUADRO, R. M. (Org.). 9th. Theoretical Issues in Sign Language Research - TILSR9. Petrópolis: Arara Azul, 2008. p. 25-32.

SUTTON-SPENCE, R. The Role of the Manual Alphabet and Fingerspelling in British Sign Language. 1994. 286 f. PhD Dissertation, University of Bristol, 1994. 
THOMASON, S.; KAUFMAN, T. Language Contact, Creolization, and Genetic Linguistics. Berkeley, CA: University of California Press, 1988.

VALLI, C.; LUCAS, C. Variation and historical change. The Linguistics of American Sign Language: A Resource Text for ASL Users Washington, D.C.: Gallaudet University Press, 1992. p. 286-291. Press, 2000.

Linguistics of American Sign Language. Washington, DC: Gallaudet University

XAVIER, A. N.; BARBOSA, P. Diferentes pronúncias em uma língua não sonora? Um estudo da variação na produção de sinais da LIBRAS. D.E.L.T.A, 30.2, p. 371-413, 2014.

WATERS, D.; CAMPBELL, R.; CAPEK, C.; WOLL, B.; DAVID, A.; McGUIRE, P.; BRAMMER, M.; MacSWEENEY, M. Fingerspelling, Signed Language, Text and Picture Processing in Deaf Native Signers: The Role of the Mid-Fusiform Gyrus. In: Neuroimage, 35, p. 1287-1302, 2007.

WEINREICH, U.; LABOV, W; HERZOG, M. I. Fundamentos empíricos para uma teoria da mudança linguística. Tradução de Marcos Bagno. São Paulo: Parábola Editorial, 2006 [1968].

Recebido em: 30/08/2016

Aprovado em: 05/03/2017 